\title{
Experiences of adult siblings of those with developmental coordination disorder (DCD): a qualitative study
}

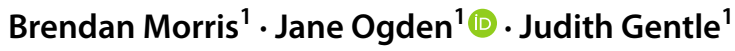

Accepted: 17 November 2021

(c) The Author(s) 2021

\begin{abstract}
This qualitative study explored the childhood experiences of growing up with a sibling with Developmental Coordination Disorder (DCD) to offer an 'outsider's' view of this condition. Ten individuals who had grown up with a sibling with DCD were interviewed about their experiences. Data were analysed using Thematic Analysis. Analysis described three main themes: i) 'witnessing the challenges for their sibling with DCD' ii) 'experiencing the impact on the family'; iii) 'a vacuum of knowledge'. Not all experiences were negative and transcending these themes was the notion 'resolution and finding benefit' highlighting access to support, being more empathic and resilient, becoming a role model for others and finding success. Participants play witness to their sibling's experiences which can often be negative sometimes impacted by a vacuum of knowledge but they also describe how a diagnosis of DCD comes with some benefits which are discussed in the context of 'posttraumatic growth'.
\end{abstract}

Keywords Developmental coordination disorder (DCD) $\cdot$ Qualitative $\cdot$ Siblings $\cdot$ Benefit finding $\cdot$ Post traumatic growth

\section{Introduction}

\section{Developmental Coordination Disorder (DCD) and its Impact on the Individual}

Developmental Coordination Disorder (DCD), sometimes known as Dyspraxia in lay terms, is estimated to be approximately 5\% of the population (DSM-5, American Psychiatric Association, 2013). The disorder substantially reduces an individual's ability to acquire and execute motor skills to an extent that it significantly interferes with academic achievement and/or activities of daily living (American Psychiatric Association, 2013). The motor difficulties are not resolved with practice or time, and they continue into adulthood (Kirby, 2011). The disorder is also commonly associated with numerous secondary social, emotional,

Jane Ogden

J.Ogden@surrey.ac.uk

Brendan Morris

brendanjmorris96@gmail.com

Judith Gentle

J.Gentle@surrey.ac.uk

1 School of Psychology, University of Surrey, Guildford, Surrey GU2 7XH, UK behavioural difficulties which arise from the culmination of limited motor skills and the frustration experienced when struggling to complete basic daily activities (Missiuna et al., 2004). For example, experiences of repeated failure can lead individuals with DCD to avoid social activities, particularly in childhood, such as sport and play (Cairney, 2008) and instead opt to engage in passive, solitary activities (Poulsen, 2008) which can negatively impact upon their self-esteem (McWilliams, 2005) and self-efficacy (Batey et al., 2014). Individuals with DCD also have an increased risk of mental health problems throughout childhood (Lingam et al., 2012) and adolescence (Harrowell et al., 2017). Despite the wide array of difficulties that can arise from DCD, this condition is still largely misunderstood and under-supported in society. Fewer than a third of physicians have an awareness of the secondary consequences of DCD (Wilson et al., 2013), just $23 \%$ of GPs have any knowledge of the condition, with only $9 \%$ ever diagnosing it in their careers (Harris et al., 2015) and even when DCD is diagnosed, $43 \%$ of individuals receive no formal support for the condition (Alonso Soriano et al., 2015). 


\section{The Impact of DCD on the Family}

Given the prevalence and potential impact of DCD, over recent years there has been an increased interest as to how DCD not only affects the individual, but also their parents and siblings. For example, Stephenson and Chesson (2008) found that DCD can have a pronounced effect on the psychological well-being of mothers, who reported feeling isolated and stressed due to the lack of support given for their child's condition. Likewise, Novak et al. (2012) reported that parents of children with DCD often had to become 'experts' on the condition due to a lack of good quality support and research indicates that having a child with DCD can negatively impact upon family quality of life and parental mental health, with a lack of support from medical and educational professionals cited as the primary source of stress (Cleaton et al., 2019). Some research has also explored the impact on siblings. For example, mothers have stated that the time invested in their child with DCD meant they were unable to be fully supportive of their other children (Stephenson \& Chesson, 2008). Likewise, Cleaton et al. (2019) concluded that $87 \%$ of mothers believed that their child's DCD had a significant impact on their other children in terms of receiving less attention than their sibling, resulting in jealousy; feeling embarrassed, upset or frustrated by their sibling's DCD, particularly around peers; being worried about their sibling with DCD; being unable to do activities that they enjoyed because their sibling was unable or unwilling to do them.

\section{The Role of the Sibling}

Research has therefore explored the impact of DCD on the individual themselves, on their parents and the parent's views of the impact of the siblings. To date, no research has explored the experience of the siblings directly. Sibling relationships are unique and sometimes referred to as the 'marathon runner' of human relationships, because they are typically the longest relationship in life (Green, 2013). Additionally, as siblings typically grow up in the same household, they generally spend more time with each other during childhood than with anyone else (Whiteman et al., 2011). Consequently, through their interactions with each other, siblings can develop skills of emotional intelligence, negotiation and problem solving (McHale et al., 2012) and can acquire positive traits such as prosocial behaviour (Brody et al., 2003) and empathy (Tucker et al., 1999). Much research has explored the effects of growing up with a sibling with a disability with conditions other than DCD. For example, Milevsky (2014) concluded that siblings of children with disabilities may be at greater risk of developing emotional difficulties such as anxiety and depression. This maladjustment framework, however, has been criticised for neglecting the potential benefits of growing up with a sibling with a condition (Cuskelly, 1999). Some research has therefore started to focus on the positive consequences of growing up with a sibling with a disability suggesting that siblings of those with intellectual disabilities, chronic illnesses or developmental disorders such as Autism Spectrum Disorder (ASD) may exhibit elevated levels of tolerance, understanding, caring and empathy (Mulroy et al., 2008; Moss et al., 2019).

\section{In Summary}

Research has therefore explored the impact of DCD on the individual with DCD and their families. Some research has also explored the experiences of those growing up with a sibling with other conditions such as chronic illnesses and ASD. To date, however, no research has focused on individuals with siblings with DCD. The aim of the present qualitative study was therefore to explore the experiences of those who have grown up with a sibling with DCD and their views of the impact upon the participant themselves, the person with DCD and the broader family. The use of a qualitative approach facilitates an in-depth analysis of experience (Sutton, 1993) and the focus on siblings reflects the value of an 'outsider' rather than an 'insider' perspective (Olson, 1977). Olson (1977) argued that an 'insider' is a member of the group being researched, whereas an 'outsider' is somebody who has observed the behaviour of the 'insider'. Whilst insider perspectives are important to understand, outsiders can provide a more detached perspective, less influenced by emotion (Furman \& Buhrmester, 1985). In the context of DCD this enables an exploration of the sibling's interaction with the person with DCD as they were growing up together with their perspectives on the ways in which having DCD impacted upon their sibling's own experiences. Furthermore, sibling relationships are generally strong, often more egalitarian and symmetrical than relationships with family members of a different generation and individuals with difficulties often turn to their sibling to ask questions and discuss things they are not comfortable discussing with parents (Bryant, 1992). Therefore, siblings of individuals with DCD may be able to provide a unique insight into the disorder as they have been a close witness to their sibling's experiences and offer an outsider's perspective. The key research question was therefore 'what are the experiences of those who have grown up with a sibling with DCD with a focus on their views of the impact upon the participant themselves, the person with DCD and the broader family'. There were no specific hypotheses as this was a qualitative study. 


\section{Method}

\section{Design}

This study used a qualitative design with semi-structured telephone interviews to collect in-depth accounts of participants' experiences of growing up with a sibling with DCD.

\section{Sample}

Whilst DCD is the formal diagnostic term, dyspraxia is more commonly used in lay language. Participants $(n=10)$ were therefore recruited via opportunity and snowballing sampling from DCD and Dyspraxia support pages on social media and posters around the university campus. The advert asked 'Do you have a brother or sister with Dyspraxia (Developmental Coordination Disorder / DCD)?'. Inclusion criteria were aged at least 18 years, to have grown up in a household with at least one sibling formally diagnosed with DCD and to not have a diagnosis of DCD themselves. At the start of the interviews the participants were asked to confirm that their sibling had received a formal diagnosis of DCD from a health professional. At the outset, we aimed to recruit sufficient participants to give us an in-depth insight into the experience of growing up with a sibling with DCD. It was predicted that this would be between 10 and 15 participants. In total, 10 participants ( 3 males, 7 females) were recruited to take part in the study who reported they had a sibling with a formal diagnosis of DCD. At this point it was felt that saturation had been reached and that no new experiences were being described. The participants were aged between 18 and 55 years $(M=25.3$ years). Whilst one participant was much older than the others, they were included in the analysis to provide their own perspective and to provide insights into to any differences between the generations. No clear differences, however, were noted between this person's experiences and those of the younger participants. All resided in the UK and all identified their ethnic group as white. The participants' siblings with DCD $(n=12 ; 7$ Males, 5 Females), were aged between 13 and $56(M=28.1)$ (two participants had both an older and younger sibling diagnosed with DCD). All participants were given a pseudonym. Participant demographics are shown in Table 1.

\section{Procedure}

Following consent, a mutually convenient time for the telephone interview was arranged. Telephone interviews were deemed the most appropriate method of data collection as it enabled participation from a geographically diverse sample that could not be obtained for face-to-face
Table 1 Participant demographics $(\mathrm{n}=10)$

\begin{tabular}{llll}
\hline $\begin{array}{l}\text { Participant's } \\
\text { Pseudonym }\end{array}$ & $\begin{array}{l}\text { Participant's } \\
\text { Age and } \\
\text { Gender }\end{array}$ & $\begin{array}{l}\text { Participant's } \\
\text { Siblings Age and } \\
\text { Gender }\end{array}$ & $\begin{array}{l}\text { Total number of } \\
\text { children in the } \\
\text { household }\end{array}$ \\
\hline Annie & $22, \mathrm{~F}$ & $24, \mathrm{~F}$ & 2 \\
Leonie & $55, \mathrm{~F}$ & 56, F & 3 \\
Jasmine & $23, \mathrm{~F}$ & $25, \mathrm{~F} \& 13, \mathrm{M}$ & 3 \\
Emma & $19, \mathrm{~F}$ & $18, \mathrm{M}$ & 2 \\
Zakk & $18, \mathrm{M}$ & $10, \mathrm{M} \& 22, \mathrm{M}$ & 6 \\
Michelle & $18, \mathrm{~F}$ & $12, \mathrm{~F}$ & 3 \\
Patrick & $31, \mathrm{M}$ & $29, \mathrm{M}$ & 2 \\
Stacey & $26, \mathrm{~F}$ & $29, \mathrm{~F}$ & 3 \\
Robert & $23, \mathrm{M}$ & $18, \mathrm{M}$ & 3 \\
Laura & $18, \mathrm{~F}$ & $25, \mathrm{M}$ & 3 \\
\hline
\end{tabular}

interviews. Additionally, research indicates that telephone interviews may allow participants to feel more relaxed and able to disclose personal or sensitive information, leading to more open and honest responses (Novick, 2008). All interviews were conducted, audio taped and transcribed verbatim by the researcher and stored securely. Interviews lasted between 15 and 35 min and during March and July 2020. Once completed, participants were given the opportunity to ask questions or make comments about the study. The study was granted a favourable ethical opinion from the University Ethics committee. Participants were not paid for their time.

\section{Interview Schedule}

The interview schedule drew upon previous research exploring the experiences of growing up with a sibling with a disability (eg. King et al., 2016) and narratives of mothers of individuals with DCD (Cleaton et al., 2019: Novak et al., 2012). The schedule included the following questions which were designed to start broad in order to set the scene and then to access both the positive and negative aspects of DCD to try to create balance. Prompts were added where deemed appropriate: i) Can you tell me about you and your family and how you all got on growing up? ii) When did you become aware of (your sibling's) diagnosis? iii) Do you think that your sibling's diagnosis has had an impact on yourself or other members of your family? If so, how? iv) Do you think (your sibling's) diagnosis effected your relationship with each other, or other members of your family? v) What were some of the best things about being a sibling to (your sibling)? vi) What were some of the difficult things of being a sibling to (your sibling)? vii) What helped you deal with the difficult things? viii) Did you ever worry about (your sibling) growing up? 


\section{The Role of the Interviewer}

The interviews were conducted by BM who has DCD which may have influenced the findings of this study. Therefore, whilst this enabled BM to show empathy and engage with participant's experiences, he was also aware of his own preexisting experiences and beliefs relating to the disorder. To minimise any bias, questions were mostly open-ended (apart from those eliciting more factual responses) and designed to be non-suggestive. Additional prompts and follow up questions were used in a limited way only when appropriate in order to keep to the interview schedule. Furthermore, the findings were discussed within the research team to ensure the final themes were reflective of the data and not just a product of his own expectations and biases. Both BM and JO are trained in qualitative methodology including conducting qualitative interviews and qualitative data analysis.

\section{Data Analysis}

Interviews were recorded, transcribed verbatim and analysed using thematic analysis to "provide a flexible and useful research tool, which can potentially provide a rich and detailed, yet complex account of data' (Braun $\&$ Clarke, 2006, p5). An inductive, 'bottom-up' approach was adopted to allow the creation of phenomenological data which the researcher could then develop into themes. The analysis followed the five stages set out by Braun and Clarke (2006) to ensure robustness: 'data familiarisation', 'initial coding generation', 'searching for themes', 'reviewing and refining themes' and 'theme definition and labelling'. The researcher who carried out the interviews (BM) read through each transcript three times to familiarise themselves with the data. JO then read through 3 transcripts identified by BM to familiarise herself with the data. JO and BM then discussed the interviews and considered initial key ideas and codes. BM then coded each transcript for pertinent information relating to participants' experiences of their sibling's DCD. JO and BM then discussed these codes and together collated and organised them into several prospective themes that appeared representative of the data. This was an iterative and ongoing process involving many discussions between JO and $\mathrm{BM}$ as several themes were considered before the finalised configuration was selected. Themes and subthemes were then amended to include those that could be explicitly supported by quotes from the data. This eventually resulted in the final thematic map and the identification of exemplar quotes. BM took field notes during the interviews and discussions concerning the data commenced from the start of data collection to consider how the interviews were progressing, whether the questions asked were eliciting sufficiently open responses and whether the interviewer's style was open enough. This led to some minor changes in the wording of the questions and the ways in which the interviews were conducted. Formal analysis commenced once all interviews had been completed and transcribed.

\section{Results}

Participants described their experiences of growing up with a sibling with DCD drawing upon their own experiences and those of their sibling. Analysis of the interviews described three main themes relating to: i) 'witnessing the challenges for their sibling with DCD' reflecting the practical, psychological and relational difficulties observed by the participant ii) 'experiencing the impact on the family' reflecting the personal and family challenges experienced by the sibling living with a person with DCD; iii) 'a vacuum of knowledge' illustrating how these challenges were exacerbated by a lack of awareness and understanding of the nature of DCD often creating a delay in getting support and a diagnosis. Not all experiences were negative, however, and transcending these themes was the theme of 'resolution and finding benefit' and an acknowledgement of the benefits of having a diagnosis of DCD, the positive traits developed due to DCD and success stories. These themes and subthemes are illustrated in the thematic map (Table 2).

Table 2 Thematic map

\begin{tabular}{lll}
\hline Themes & Subthemes & Transcending Theme \\
\hline Witnessing the challenges for their sibling with DCD & Practical and psychological challenges & Resolution \\
& Negative experiences of others & 1. Benefits of diagnosis \\
& Fear of being different & 3ositive Traits due to DCD \\
Experiencing the impact on the family & Sibling rivalry & \\
& Family relationships & Lack of awareness \\
A vacuum of knowledge & Lack of understanding & \\
\end{tabular}




\section{Theme 1: Witnessing the Challenges for their Sibling with DCD}

Participant's described witnessing various challenges faced by their sibling arising from their DCD. Some were practical challenges which were often the first indicators that their sibling may have DCD which in turn lead to psychological challenges including reduced self-esteem and self-efficacy. Some challenges related to negative experiences of others, specifically teachers and peers and some challenges reflected their sibling's fear of being different. The subthemes 'practical and psychological challenges', 'negative experiences of others' and 'fear of being different' will now be described.

\section{Practical and Psychological Challenges}

Participants described how many initial indicators of their sibling's DCD were often displayed through bumping into things or dropping objects, as well as through tasks that required motor skill proficiency such as riding a bike. As Emma said of her brother:

"It was the hand eye co-ordination: buttonholes and tying laces and stuff. Yeah it was mostly just fine motor skills, he never really got a handle on them." (Emma)

Similarly, Zakk said:

"He had trouble learning to ride a bike and everything. When he was young, he was quite clumsy I guess, he tripped and fell over all the time" (Zakk).

Challenges were also apparent at school during tasks that required fine motor skills, speed and legibility of handwriting was the most frequently reported practical difficulty by participants. As Robert said:

"His English teacher said his ability was good, but his handwriting wouldn't have allowed him to progress to $a C^{\prime \prime}$ (Robert)

These practical challenges in turn often led to the sibling experiencing emotional problems such as feeling low, low self esteem and ruminating on their mistakes:

"That feeling of not being good at something (P.E) and having to do it was really taxing for her, when it was being repeated over and over again". (Leonie)

Furthermore, participants described how repeatedly comparing themselves to their peers led their siblings to feel as if they were falling behind, which at times made them both apathetic and reluctant to attempt certain tasks again in the future.
"If he can't do something straight away he does become de-motivated quite easily, again, I think he just wants to be able to do stuff, and again I think that's because he can see other people being able to do it straight away. You know, it's affected him". (Jasmine)

Some participants also reported how repeated failures led to their siblings expecting to fail thereby exacerbating their anxiety:

"The fact that she knows something could go wrong makes her more worried because she's looking for it. She's always thinking 'ooo something will go wrong in a minute' and then because she's worrying about it, it does go wrong." (Michelle)

\section{Negative Experiences of Others}

Participants also described how their sibling was exposed to criticism from others throughout their childhood particularly their teachers and peers. For example, participants described how teachers would often attribute their sibling's difficulties to a lack of effort or intelligence, without considering the possibility of DCD. This led to some harsh and critical comments from some teachers which were internalised leading to low self esteem:

"A lot of teachers said stuff like 'oh, you'll never be good at that' or 'oh, you're just not academic' so I think she sometimes thought 'oh I'm just useless at that, I'm never going to be good at it"'. (Annie)

Sometimes, teachers would be reluctant to support their students with DCD, even after they were made aware of their diagnosis and had set up a support plan with the school.

"She had a proper plan that they co-ordinated with the school SENCO. And there were lots of things that were supposed to happen in class that didn't and at the very beginning of the year the teacher had been very happy to say 'yes we'll do this, yes we'll do that' and every week or every other week we would say to Martha 'oh how's this going on' or 'how's that going on' and she'd say 'oh, I don't do that.", (Michelle)

Participants also described how their siblings had been criticised by their peers. As Michelle said:

'Within the first term she dropped something when she was doing a science practical and everyone was looking and laughing at her' (Michelle).

Likewise, Jazmin described how upsetting these comments could be particularly as a teenager:

'There wasn't the understanding of the condition. When you were in that teenage stage of life it was very 
challenging when peers go 'Oh well. If I can do it why can't you!' (Jazmin).

\section{Fear of Being Different}

The final component of the challenges witnessed by the participants was how their siblings tended to compare themselves unfavourably with others which could lead them to worry about being perceived as strange or different. For example, as Zakk said of his brother:

"It's being able to do things that other people his age do, so being able to ride a bike, ride a scooter. He just wants to use his motor skills like any other person can and sometimes he struggles with that, I think sometimes it really frustrates and upsets him." (Zakk)

The fear of being different often meant that participants' siblings would not seek support, as they were afraid it would make them stand out or negatively influence their peer's perceptions of them.

"I think my biggest worry was he doesn't really like being seen as different. So, for example he doesn't want to use extra time, I specifically have to talk him into using it. He doesn't take advantage of the things he's given to accommodate for things that could set him back." (Emma)

Likewise, Michelle described her sister's experiences:

"There's a separate building on the school site for special needs and anything like that. But she doesn't want to go in because she doesn't want people to think she's weird. She doesn't want to be seen as different and she doesn't want to go to people she doesn't know." (Michelle)

In summary, this first theme illustrates the challenges witnessed by the participants including practice and psychological challenges, negative experiences of others particularly teachers and peers and a fear of being different. In turn these challenges often led to anxiety and low self esteem and could act as a barrier to seeking help.

\section{Theme 2: Experiencing the Impact on the Family}

As well as describing the challenges faced by their sibling with DCD, participants also recounted their first-hand experiences of the impact of their siblings' condition on themselves and their family.

\section{Sibling Rivalry}

At times participants described their own frustration or anger with their sibling's DCD, particularly when they were younger. This was sometimes caused by their sibling's slowness to learn certain skills which in turn had a negative impact on the sibling relationship and a sense of rivalry for parental attention. As Emma described:

"I was expected by my mum to do things a lot earlier than he was, I think it made me angry at him because she was more focused on him because he needed the help, but when I was younger I didn't recognise that it was because he needed it. I just thought he was favoured more than me". (Emma)

This was also clearly described by Stacey who described 'tension' and having to hide being able to ride a bike and tie shoelaces from her sister who was 3 years older than her:

"When I was a child I think it had an impact on me ..So, we learned to ride a bike at the same time.., even though there's a three year difference...I was able to do it before she was, which created quite a lot of tension. .. I wasn't able to say that I'd learnt how to do it or celebrate it because it was too difficult for her. Lots of other things like that as well, like learning how to tie laces... I had to practice secretly, and I could never tell anybody that I'd learnt how to tie laces. I picked up things really quickly and it would really annoy my sister because of how far behind she felt." (Stacey).

\section{Family Relationships}

Participants also described how their sibling's DCD had an impact on other members of the family. In particular, they described the frustration experienced by their parents. For example, Robert described:

"Back when we didn't know, when, like he's not great at cutlery and when we sat down for a meal he was struggling, doing it wrong or holding it wrong and just couldn't do it. Dad would get frustrated trying to teach him how to do it" (Robert).

Likewise, participants also reported observing similar emotional responses in their younger siblings without a DCD diagnosis. As Michelle said of her younger brother:

"He doesn't understand that Martha isn't being clever when she makes mistakes or when she drops things and it just infuriates him." (Michelle).

Furthermore, they also illustrated how their sibling's condition and the resulting psychological challenges they faced were a source of worry for all the family. For example, as Stacey said:

"I think the fact that she felt so different with everything made her feel quite isolated and lonely and that 
was challenging for everybody. Because we couldn't fully understand." (Stacey)

This second theme therefore illustrates the participants' own experiences of the impact of having a sibling with DCD on themselves and other members of the family in terms of sibling rivalry, frustration and worry.

\section{Theme 3: A Vacuum of Knowledge}

Participants therefore described the challenges they had witnessed experienced by their sibling together with the impact on themselves and their family. The third theme relates to the notion of a vacuum of knowledge, whereby participants illustrated how these experiences existed within: i) a lack of awareness of what a DCD diagnosis was and ii) a lack of understanding of its symptoms and how it affects the individual after diagnosis.

\section{Lack of Awareness of DCD}

Apparent across all interviews, regardless of the age of the participant and their sibling, was a lack of awareness of the existence of DCD in society, specifically among teachers, peers and families with several participants reporting that their sibling's DCD diagnosis was the first time they had heard the terms 'DCD' or 'Dyspraxia' and nearly all saying that increasing its awareness was key.

"I just think that dyspraxia needs a higher profile out there, it just needs more awareness. Yeah, I think that's the biggest change I would want to see." (Jasmine)

This lack of awareness could be seen as underpinning many of the challenges experienced by the siblings. It was most apparent, however, in the accounts of those with siblings who had not been diagnosed until later in life. Therefore, even though these participants reported how their siblings had shown difficulties in motor skills from an early age at both school and at home, a lack of awareness of DCD by both teachers and their family meant that these difficulties went undiagnosed. This in turn meant that the sibling was left without sufficient psychological and practical support exacerbating the impact of their condition.

"In our family, had we had the diagnosis it would've helped them understand and get more support. Because I think they would have known what was going on." (Annie)

This highlights the problems of not having a diagnosis which limited the parents' ability to seek help. The absence of a label, however, also limited the families sense making and understanding leaving them feeling confused, helpless and frustrated. As Robert described:
"Once we found out (about his diagnosis) it definitely took that frustration away and dad just came to the realisation that he wasn't going to be able to do that, the fine motor control wasn't there." (Robert).

Robert also described how the diagnosis helped his parents alleviate their sense of guilt:

"It (the diagnosis) took a lot of pressure off them thinking they had done anything wrong. You know 'why can't he do these things?' to giving them a full explanation as to why he can't do those things". (Robert)

The benefit of a diagnosis was sometimes contrasted with better known health conditions, which have a more common diagnosis where treatment was much more accessible.

"Where I had anxiety, she (participant's mother) was able to take me to a therapist and that helped. Whereas for Diana (participant's sister with DCD) they sort of thought there was nothing they could do for her problems." (Annie)

This lack of awareness of DCD, also underpinned the reactions of teachers who would sometimes attribute their pupil's difficulties to other factors, such as laziness or a lack of intelligence.

"I think other people couldn't get why she couldn't do certain things. Especially in that teenage phase of life it's really challenging to face this attitude of others going 'oh well if I can do it why can't you', I think that impacted her when she was young." (Jasmine)

This is likely to have contributed to some of the negative experiences and criticism that participant's siblings faced during their childhood.

\section{Lack of Understanding}

Even when teachers, peers and families had an awareness of DCD, a lack of understanding of the disorder and its associated difficulties permeated the participants' experiences and those of their siblings. As Zakk described:

"Whilst some people know DCD is a thing, people sort of forget, or don't know how it impacts your whole life". (Zakk)

This was also an issue within the families themselves. Whilst all participants knew about the motor difficulties associated with DCD, many of them were unaware of the other associated difficulties such as organisation and planning difficulties.

"Even to this day there are moments where I'm like 'oh okay, I didn't realise that (organisation skills) was all part of it'". (Jasmine) 
Nevertheless, understanding had tended to increase within families over time and most participants were very knowledgeable about their siblings' condition. Lack of understanding was, however, more commonly an issue for teachers and several participants expressed their frustration at teacher's unwillingness to support their siblings, even after they were aware of their diagnosis. As Michelle said:

"She had a bobble cushion to help with her hypermobility for sitting cross-legged in front of the board, but the teacher wouldn't let her use it. We tried talking to the teacher and she said 'well why can't she sit on the floor like everyone else?"' (Michelle)

Further, this lack understanding was seen as a having a longlasting negative impact, even when it was just one comment from one teacher and several participants reported how bad experiences with a teacher's prevented their sibling from seeking support for a long time through fear of judgement. As Michelle described:

"Her secondary school have been quite understanding, they've tried to work with her, but where she has not had so much support at primary school, she's too scared to talk to teachers about it. Because of one bad experience, she doesn't want to reach out." (Michelle)

In summary, this third theme illustrates how the challenges both witnessed and experienced by the participants were often underpinned by a vacuum of knowledge illustrated by a lack of awareness and understanding of DCD. In particular, this vacuum of knowledge led to delayed diagnosis, a feeling of frustration, confusion and upset and often deferred help seeking either through not knowing that such help was available or through fear of judgement which in turn exacerbated the difficulties experiences by those with DCD.

\section{Transcending Theme: Resolution and Finding Benefit}

Participants therefore described many challenges for the sibling with DCD, themselves and the family which were exacerbated by a vacuum of knowledge surrounding the condition. These negative consequences, however, tended to diminish over time and the majority also indicated that there were many benefits to having DCD suggesting a degree of adjustment after a period of struggle. This process of resolution can be described in terms of 'Diagnosis as a form of support'; 'Positive traits developed due to DCD' and 'Success stories'.

\section{Diagnosis as a Form of Support}

Participants described how the psychological and physical difficulties experienced by their sibling tended to alleviate with time. In particular, they described the beneficial impact of having a diagnosis which enabled both the sibling and the wider family to seek help where necessary and facilitated a process of adaptation and acceptance. As Annie said of her sister:

"Since she's had the diagnosis, she's much more able to say 'oh okay that's just something I'm not able to do', and she just gets on with it a lot more. She's just accepted some things she won't be able to do." (Annie)

\section{Positive Traits Developed Due to DCD}

Many participants also described how the adversity faced by their sibling in early life had helped them to become more resilient. They also described how this resilience had helped them to become more empathetic and caring.

"I think because she's had to overcome things, that if anybody has a problem, she will help people with them or find a way for people to get around them". (Annie)

Likewise, Stacey said:

"I think it (Her DCD) made us more empathetic um, and more open to the fact that people are different." (Stacey)

The benefits of DCD were not always for the sibling with DCD but also for the brother or sister being interviewed. For example, those with older siblings with DCD often described them as role models who had inspired them to be more resilient themselves:

"I actually always looked up to my sister growing up because I always felt she took it on the chin and carried on regardless. I think she always had such a good 'no I'm not going to let it hold me back' attitude." (Jasmine)

And Stacey described how all the family had benefitted from her sister's condition:

"She opened all of our eyes to different experiences in life and how you can see the world differently, good and bad. She makes us think, she makes me think and she makes me learn a lot more, she's very kind and supportive and funny. She has a different personality and likes and dislikes to me which makes her a lot more interesting". (Stacey)

\section{Success Stories}

Participants also described how their siblings with DCD had gone on to live happy and successful lives, adapting to the difficulties they faced. The participants therefore expressed respect and admiration for their sibling's achievements. 
"It's always been interesting to me watching him play slap bass guitar or the drums. In many ways he's incredibly co-ordinated and dexterous. When you contrast that with the kid who couldn't catch a ball it's actually amazing". (Patrick)

Not all participants felt that their sibling had benefitted from their diagnosis of DCD. In fact, Robert described how he felt his brother was going to be a success with or without his condition:

"It (his diagnosis of DCD) made it clear why he was struggling with some things. But I don't think it's changed the way he's gone about progressing with his life. You know he was always good on computers so that's what he's decided to go ahead with." (Robert)

In summary, participants described the difficulties faced by their siblings and how these had been exacerbated by a vacuum of knowledge. Their interviews, however, also illustrated a more positive account of having a sibling with DCD and showed how over time they had begun to see the benefits both of having DCD and having a sibling with DCD having watched their sibling grow up and achieve happy and successful lives.

\section{Discussion}

The aim of the present study was to give participants the opportunity to describe their experiences of having a sibling with DCD and to offer an outsider's perspective on this condition. Analysis described three main themes. The first theme relating to the 'witnessing the challenges for their sibling with DCD' reflects much of the existing research. For example, participants in the present study described witnessing practical challenges with daily tasks such as tying shoe laces, handwriting and riding a bike and psychological challenges such as low self-esteem and anxiety in line with literature suggesting that these practice problems are core to DCD and can increase the risk of mental health difficulties (e.g. Lingam et al., 2012). Furthermore, the focus on negative experiences from teachers and peers highlights how some of these difficulties may arise with poor motor coordination leading to frustration and negative interactions with others, or bullying, which in turn can result in poor self-esteem and internalisation (Rigoli et al., 2017). This aligns with the environmental stress hypothesis (Mancini et al., 2016), and suggests that it is not the practical challenges per se which cause subsequent problems but the ways in which others react to them. Further, the 'fear of being different' parallels findings that individuals with DCD make unfavourable comparisons with their peers (Green \& Payne, 2018), which alongside a tendency to avoid situations in which their difficulties might be exposed (Barnett et al., 2013) can contribute to low self-esteem, embarrassment, and social isolation (Jarus et al., 2011.

The second theme 'experiencing the impact on the family' is a more novel finding and illustrated the participant's own experiences of growing up with the sibling with DCD were sometimes embedded with feelings of frustration, tension, worry and a degree of sibling rivalry as they competed for parental attention. Previous research indicates that mothers worry that time invested in their child with DCD may detract with that spent with their other children and worry that this could cause a sense of jealousy or frustration (Stephenson \& Chesson, 2008; Cleaton et al., 2019). The results from the present study provide some confirmation of these maternal worries and indicate these experiences from the sibling's own perspective.

The third theme related to a 'vacuum of knowledge' illustrated by a lack of awareness and understanding of DCD from teachers, peers and family which was apparent in the interviews regardless of the participant's age and is also well documented in the literature (e.g. Wilson et al., 2013). The results from the present study also illustrate, however, how this vacuum of knowledge exacerbated or sometimes even caused the negative experiences being faced during childhood. In particular, accounts indicated that a lack of tolerance from others, together with frustration or even critical comments (due to ignorance rather than maliciousness), not only created psychological difficulties but at times delayed diagnosis preventing access to appropriate support. Furthermore, such delays also seemed to embed problems such as lowered self-esteem and anxiety making them harder to reverse even after a formal diagnosis when help had been made available.

Not all experiences of having a sibling with DCD were negative, however, and transcending all accounts was a theme of resolution in which participants found benefits in their sibling's condition for themselves, the broader family and their sibling and illustrated a sense of resolution. In particular, they described how having a diagnosis of DCD gave their sibling access to appropriate support, how it seemed to have made them a better person with increase empathy and resilience, how the participant themselves and their family had also benefitted by becoming likewise more resilient and open to difference and how the sibling with DCD had managed to live a successful and fulfilling life achieving the respect and admiration of those around them. Therefore, in line with criticisms of a maladjustment framework (Cuskelly, 1999), and research indicating benefits for siblings of those with other developmental disorders such as ASD (Mulroy et al., 2008; Moss et al., 2019), the results from the present study indicate benefits not only to the person with DCD but also those around them. 


\section{Implications for Theory, Research and Practice}

Participants therefore described several negative consequences of DCD which were exacerbated by a vacuum of knowledge. They also however, illustrated a state of resolution and an ability to find benefit in their sibling's condition. These findings have implications for theory, research and practice. In terms of theory, participants' accounts reflect the notion of benefit finding and the concept of Post Traumatic Growth which is a positive psychological change resulting from experiencing adversity (Tedeschi \& Calhoun, 2004). To date, the concept of posttraumatic growth has been applied to physical illnesses such as cancer, HIV or heart disease, with research indicating that many individuals perceive benefits from being ill such as a greater appreciation of life, strengthened family relationships, a positive change in self-perception, greater resilience as well as greater optimism and positive affect (Seery et al., 2010; Pressman et al., 2019). The results from the present study suggest that such benefit finding may also be experienced by those with developmental disorders such as DCD. It may, however, have needed an outsider's insight into growing up with a sibling with DCD to enable this more positive outcome of DCD to be explored.

In terms of research, future research could focus further on the potential benefits of DCD and using a longitudinal design could explore how these benefits develop and the factors which promote a more positive experience of this condition. Furthermore, research could unpack the family dynamics which promote a better experience for both the child with DCD and their siblings in terms of factors such as birth order, age of diagnosis, gender of siblings and familial responses to the condition both pre and post diagnosis. In line with this, interventions could then be developed and evaluated to help support those with DCD and their families to mitigate against the development of psychological problems such as low self esteem and anxiety.

In terms of practice, the present study highlights the need to challenge the vacuum of knowledge and raise awareness and understanding of this condition. This could be achieved through further research, through public information campaigns, through the inclusion of those with DCD in the media in adverts and TV dramas and through school based educational interventions to promote discussion about the issues faced by those with DCD in both adults and children. This would hopefully promote help seeking and limit delays in diagnosis thereby minimising the more negative consequences of this condition. In addition, however, the findings also highlight the more positive aspects of DCD both for the individual with DCD and for their siblings and wider family and friends. Campaigns could therefore also emphasise these more positive components of DCD and in line with the more recent emphasis on neurodiversity and the celebration of difference this could enable both those with DCD and those around them to see the condition in a more positive light.

\section{Methodological Limitations}

There are, however, some limitations with the present study that need to be considered. First, the study was retrospective in its design with participants reflecting back upon their childhood memories and describing the experiences of their siblings through the lens of the present time. Accordingly, their current perspectives may well have influenced what they recalled and the emphases they placed on past events. Second, given the age of the participants and their siblings, changes in support for those with DCD may mean that more recent generations have grown up in a more aware and understanding world. Third, the qualitative nature of the design together with the sample size means that it is not appropriate to unpack individual differences in experiences relating to factors such as age, gender and birth order which require a larger sample and a more quantitative approach. Fourth, no details were taken about co diagnoses which may have influenced the findings. Further, whilst interviewing siblings provided an outsider perspective on growing up with DCD, this once removed account means that issues attributed to DCD are only attributed to DCD through the eyes of the onlooking sibling and may say more about this outsider's view that the view of the person with DCD.

\section{Conclusion}

To conclude, the present study explored the experiences of participants growing up with a sibling with DCD to offer an outsider's insight into this condition. Participants described witnessing their siblings practical and psychological challenges, including the negative reactions of others and a fear of being different. Further, participants described the impact on themselves and their family in terms of sibling rivalry, frustration and worry and illustrated how these more negative consequences of DCD were exacerbated by a vacuum of knowledge. Participants, however, also described many positive consequences of having DCD with their sibling considered more empathic and viewed with respect and admiration and all parties were deemed to have become more resilient. Much research indicates that DCD can have a detrimental impact upon the individual and their family. The present study supports these findings but also offers novel insights into how these detrimental processes may occur. In addition, the results also suggest several benefits of DCD for both the individual with DCD and their family and indicates that whilst finding benefit has been considered as a result of physical illness it may also be characteristic of those with DCD but may need an outsider's view to identify it. 
Acknowledgements The authors are grateful to a number of Dyspraxia Support groups for help with recruitment for this study.

Availability of Data and Material Interview data is not available due to the potential for identifying participants and due to the personal nature of the accounts provided.

Code Availability Not applicable.

Author's Contributions JO, BM and JG conceived of the research idea. $\mathrm{BM}$ carried out the interviews. JO and BM analysed the data. BM and JO wrote the paper and incorporated comments from JG.

\section{Declarations}

Conflicts of Interest/Competing Interests The authors have no relevant financial or non-financial interests to disclose.

Ethics Approval Approval was obtained from the ethics committee of University of Surrey. The procedures used in this study adhere to the tenets of the Declaration of Helsinki.

Consent to Participate Informed consent was obtained from all individual participants included in the study.

Consent for Publication The authors affirm that human research participants provided informed consent for publication of their anonymised quotations.

Open Access This article is licensed under a Creative Commons Attribution 4.0 International License, which permits use, sharing, adaptation, distribution and reproduction in any medium or format, as long as you give appropriate credit to the original author(s) and the source, provide a link to the Creative Commons licence, and indicate if changes were made. The images or other third party material in this article are included in the article's Creative Commons licence, unless indicated otherwise in a credit line to the material. If material is not included in the article's Creative Commons licence and your intended use is not permitted by statutory regulation or exceeds the permitted use, you will need to obtain permission directly from the copyright holder. To view a copy of this licence, visit http://creativecommons.org/licenses/by/4.0/.

\section{References}

Alonso Soriano, C., Hill, E. L., \& Crane, L. (2015). Surveying parental experiences of receiving a diagnosis of developmental coordination disorder (DCD). Research in Developmental Disabilities., 43-44, 11-20. https://doi.org/10.1016/j.ridd.2015.06.001

American Psychiatric Association. (2013). Diagnostic and statistical manual of mental disorders (5th ed.). Author.

Barnett, A. L., Dawes, H., \& Wilmut, K. (2013). Constraints and facilitators to participation in physical activity in teenagers with developmental coordination disorder: An exploratory interview study. Child Health Development, 39(3), 393-403. https://doi.org/10. 1111/j.1365-2214.2012.01376.x

Batey, C. A., Missiuna, C. A., Timmons, B. W., Hay, J. A., Faught, B. E., \& Cairney, J. (2014). Self-efficacy toward physical activity and the physical activity behavior of children with and without developmental coordination disorder. Human Movement Science, 36, 258-271. https://doi.org/10.1016/j.humov.2013.10.003
Braun, V., \& Clarke, V. (2006). Using thematic analysis in psychology. Qualitative Research in Psychology, 3(2), 77-101, Retrieved from: https://core.ac.uk/download/pdf/1347976.pdf.

Brody, G. H., Kim, S., Murry, V. M., \& Brown, A. C. (2003). Longitudinal direct and indirect pathways linking older sibling competence to the development of younger sibling competence. Developmental Psychology, 39(3), 618.

Bryant, B. K. (1992). Sibling caretaking: Providing emotional support during middle childhood. In F. Boer \& J. Dunn (Eds.), Children's sibling relationships: Developmental and clinical issues (pp. 55-69). Lawrence Elbaum Associates.

Cairney, J. (2008). What should we do to help children with DCD. Developmental Medicine and Child Neurology, 50(8), 566. https:// doi.org/10.1111/j.1469-8749.2008.03056.x.091454

Cleaton, M. A., Lorgelly, P. K., \& Kirby, A. (2019). Developmental coordination disorder: The impact on the family. Quality of life research: an international journal of quality of life aspects of treatment, care and rehabilitation., 28(4), 925-934. https://doi. org/10.1007/s11136-018-2075-1

Cuskelly, M. (1999). Adjustment of siblings of children with a disability: Methodological issues. International Journal for the Advancement of Counselling, 21(2), 111-124. https://doi.org/10.1023/A: 1005331700993

Furman, W., \& Buhrmester, D. (1985). Children's perceptions of the qualities of sibling relationships. Child Development, 56(2), 448461. https://doi.org/10.2307/1129733

Green, D., \& Payne, S. (2018). Understanding Organisational ability and self-regulation in children with developmental coordination disorder, Current Developmental Disorders Reports, 5, 34-42, Retrieved from: https://link.springer.com/article/10.1007/ s40474-018-0129-2.

Green, L. (2013). The well-being of siblings of individuals with autism. ISRN Neurology, 417194, Retrieved from: https://www.ncbi.nlm. nih.gov/pmc/articles/PMC3657443/

Harris, S. R., Mickelson, M. D., \& Zwicker, J. G. (2015). Diagnosis and management of developmental coordination disorder. CMAJ. Canadian Medical Association Journal., 187(9), 659-665. https:// doi.org/10.1503/cmaj.140994

Harrowell, I., Hollen, L., Lingam, R., \& Emond, A. (2017). Mental health outcomes of developmental coordination disorder in late adolescence, Developmental Medicine and Child Neurology, 59(9), 973-979, Retrieved from: https://www.ncbi.nlm.nih.gov/ pmc/articles/PMC5573907/.

Jarus, T., Lourie-Gelberg, Y., Engel-Yeger, B., \& Bart, O. (2011). Participation patterns of school-aged children with and without DCD. Research in Developmental Disabilities, 32(4), 1323-1331. https://doi.org/10.1016/j.ridd.2011.01.033

King, K., Alexander, D., \& Seabi, J. (2016). Siblings perceptions of their ADHD-diagnosed sibling's impact on the family system. International Journal of Environmental Research and Public Health, 13(9), 910. https://doi.org/10.3390/ijerph13090910

Kirby, A. (2011). Developmental co-ordination disorder and emerging adulthood: Not just a motor disorder. Journal of Adult Development, 18, 105-106. https://doi.org/10.1007/s10804-011-9124-0

Lingam, R., Jongmans, M., Ellis, M., Hunt, L., Golding, J., \& Emond, A. (2012). Mental health difficulties in children with developmental coordination disorder. Pediatrics, 129(4), e882-e891. https:// doi.org/10.1542/peds.2011-1556

Mancini, V., Rigoli, D., Cairney, J., Roberts, L., \& Piek, J. (2016). The elaborated environmental stress hypothesis as a framework for understanding the association between motor skills and internalising problems: A mini-review. Frontiers in Psychology, 7, 239. https://doi.org/10.3389/fpsyg.2016.00239

McHale, S. M., Updegraff, K. A., \& Whiteman, S. D. (2012). Sibling relationships and influences in childhood and adolescence. 
Journal of Marriage and the Family, 74(5), 913-930. https://doi. org/10.1111/j.1741-3737.2012.01011.x

McWilliams, S. (2005). Developmental coordination disorder and selfesteem: Do occupational therapy groups have a positive effect? British Journal of Occupational Therapy, 68. https://doi.org/10. 1177/030802260506800903

Milevsky, A. (2014). Understanding adolescents for health professionals. Springer Verlag.

Missiuna, C., Rivard, L. \& Pollock, N. (2004) "They're bright but Can't write: Developmental coordination disorder in school aged children", TEACHING exceptional children plus: 1(1), article 3. Retrieved from: http://escholarship.bc.edu/education/tecplus/vol1/ iss $1 / 3$.

Moss, P., Eirinaki, V., Savage, S., \& Howlin, P. (2019). Growing older with autism- the experiences of adult siblings of individuals with autism. Research in Autism Spectrum Disorders, 63, 42-51. https://doi.org/10.1016/j.rasd.2018.10.005

Mulroy, S., Robertson, L., Alberti, K., Leonard, H., \& Bower, C. (2008). The impact of having a sibling with an intellectual disability: Parental perspectives in two disorders. Journal of Intellectual Disability Research, 52(3), 10-18. https://doi.org/10.1111/j. 1365-2788.2007.01005.x

Novak, C., Lingam, R., Coad, J., \& Emond, A. (2012). 'Providing more scaffolding': Parenting a child with developmental co-ordination disorder, a hidden disability. Child: Care, health and development., 38(6), 829-835. https://doi.org/10.1111/j.1365-2214.2011. 01302.x

Novick, G. (2008). Is there a bias against telephone interviews in qualitative research? Research in Nursing \& Health, 31(4), 391-398, Retrieved from: https://www.ncbi.nlm.nih.gov/pmc/articles/ PMC3238794/.

Olson, P. H. (1977). Insiders' and outsiders' views of relationships: Research studies. In G. Levinger \& H. L. Raush (Eds.), Close relationships: Perspectives on the meaning of intimacy. University of Massachusetts Press.

Poulsen, A. A. (2008). Physical activity leisure-time participation of boys with developmental coordination disorder. Australian Occupational Therapy Journal, 55(4), 298. https://doi.org/10.1111/j. 1440-1630.2007.00692.x

Pressman, S. D., Jenkins, B. N., \& Moskowitz, J. T. (2019). Positive affect and health: What do we know and where next should we go? Annual Review of Psychology, 70, 627-650. https://doi.org/ 10.1146/annurev-psych-010418-102955
Rigoli, D., Kane, R. T., Mancini, V., Thornton, A., Licari, M., Hands, B., McIntyre, F., \& Piek, J. (2017). The relationship between motor proficiency and mental health outcomes in young adults: A test of the environmental stress hypothesis. Human Movement Science, 53, 16-23. https://doi.org/10.1016/j.humov.2016.09.004

Seery, M. D., Holman, E. A., \& Silver, R. C. (2010). Whatever does not kill us: cumulative lifetime adversity, vulnerability and resilience. Journal of Personality and Social Psychology, 99(6), 1025-1041. https://doi.org/10.1037/a0021344

Stephenson, E. A., \& Chesson, R. A. (2008). 'Always the guiding hand': Parents' accounts of the long-term implications of developmental co-ordination disorder for their children and families. Child: care, health and development., 34(3), 335-343. https://doi. org/10.1111/j.1365-2214.2007.00805.x

Sutton, B. (1993). The rationale for qualitative research: A review of principles and theoretical foundations, The Library Quarterly: Information, Community, Policy, 63(4), 411-430, Retrieved from: https://www.jstor.org/stable/4308864?read-now=1\&seq=1\#page scan_tab_contents.

Tedeschi, R. G., \& Calhoun, L. G. (2004). Posttraumatic growth: Conceptual foundations and empirical evidence. Psychological Enquiry, 15(1), 1-18. https://doi.org/10.1207/s15327965pli1501_ 01

Tucker, C. J., Updegraff, K. A., McHale, S. M., \& Crouter, A. C. (1999). Older siblings as socializers of younger siblings' empathy. The Journal of Early Adolescence., 19(2), 176-198. https:// doi.org/10.1177/0272431699019002003

Whiteman, S.D., McHale, S.M., \& Soli, A. (2011). Theoretical perspectives on sibling relationships. Journal of family theory \& review. 3(2), 124-139, Retrieved from: https://www.ncbi.nlm. nih.gov/pmc/articles/PMC3127252/.

Wilson, B. N., Neil, K., Kamps, P. H., \& Babcock, S. (2013). Awareness and knowledge of developmental co-ordination disorder among physicians, teachers and parents. Child: care, health and development., 39(2), 296-300. https://doi.org/10.1111/j.13652214.2012.01403.x

Publisher's Note Springer Nature remains neutral with regard to jurisdictional claims in published maps and institutional affiliations. 